\title{
Notas ecocríticas sobre A Dríade e outros contos arbóreos de Andersen
}

Ecocritical notes on The Dryad and other arboreal tales by Andersen

\section{$\underline{\underline{\text { Klaus Eggensperger }}}$}


Nos contos de Andersen, todos os seres têm a capacidade de se comunicar e agir independentemente de seu status social ou ontológico: o gafanhoto discute com um osso de peito de ganso e com a pulga (Saltadores, 1845), a sombra faz negócios com o letrado (A sombra, 1847), a roseira discute com os raios do sol e o orvalho (Which is the happiest?, 1868) $)^{2}$, e, na valeta, a agulha de passajar troca ideias com um caco de vidro (A agulha de passajar, 1845-47). No conjunto, as histórias constituem uma rede dos mais diferentes atores, caraterizada por um pluralismo de diversos modos de existência - para fazer uso de uma expressão de Bruno Latour. Pluralismo não implica necessariamente em igualdade; no universo anderseniano, a comunicação de todos e todas não garante simetria entre humanos e não humanos, inexistente até entre os humanos. Contudo, é a agência de animais, plantas, objetos naturais, artefatos, espíritos etc., que caracteriza o universo pré-moderno popular, ainda pouco influenciado/ tangido pelo esforço de desenvolver a modernidade e estabelecer dois reinos claramente separados, o da Natureza e o da Sociedade, processo que começou na Europa do século XVII (LATOUR, 2013, cap.2 ). Muitos românticos enfatizaram a visão animista do mundo, procuraram revalorizar a natureza e reespiritualizar a sociedade europeia, na qual a crescente indústria, o comércio nacional e mundial, a urbanização e a dominação tecnocientífica estavam determinando o desenvolvimento: "the Romantic's reclamation of a place for the sacred is (...) a core element of their revaluation of the natural world" (RIGBY, 2014, p. 71).

Em The Dryad (Dryaden, 1868), conto tardio de Andersen, uma castanheira jovem cresce no campo perto de Paris e se comunica através da sua ninfa pessoal, sua dríade, uma figura da poesia popular com vínculo da mitologia grega pagã:

$$
\begin{aligned}
& \text { she knew the language of people as well as that of the animals. Butterflies, cockchafers, and } \\
& \text { dragonflies - indeed, everything that could fly came to visit her, and everyone that came would } \\
& \text { gossip. They talked about the villages, the vineyards, the woods, and the old castle with its }
\end{aligned}
$$

2 As obras de Andersen que não foram traduzidas diretamente do dinamarquês para o português (ANDERSEN, 2011) são citadas em inglês. Também foi consultada uma ótima seleção de obras andersenianas em alemão, conforme as referências bibliográficas. O texto online do conto Dryaden/The dryad constante no site da Syddansk Universitet em Odense não oferece paginação. 
park, in which there were dikes and canals; down there in water also dwelt beings who in their own way could fly from place to place - beneath the water - beings with knowledge and imagination, but who said nothing, for they were too wise (ANDERSEN, 1949).

A jovem dríade escuta também as vozes humanas e participa desta maneira das falas patrióticas do padre local sobre a França, sua cultura e história. A zona rural que o narrador, nas primeiras páginas, apresenta é "o mundo pequeno" (chamado assim no Fausto goethiano), limitado, mas vívido, comunicativo, animado, uma esfera híbrida, onde a sociabilidade não é exclusivamente humana e a "Grande Divisão" (LATOUR, 2013, p. 44) entre natureza civilização ainda não está completa.

Existem vários contos de Andersen, nos quais uma árvore exerce um papel central na narrativa. Grantreet (The Fir Tree, 1845) conta a história de um jovem pinheiro que não se contenta com a rica floresta conífera em volta dele, não consegue viver a plenitude do momento presente, mas está sempre à procura de um futuro maravilhoso. Torna-se árvore de natal ricamente decorada em um casarão, mas nem as horas da sua glória durante a noite natalina consegue aproveitar, imaginando sempre aquilo que poderia acontecer no dia seguinte. Quando é descartado semanas depois, cortado em pedaços e queimado no fogo, vive tragicamente o momento da sua morte como mais pleno da sua existência. The Fir Tree é um dos muitos contos andersenianos que se dirigem ao mesmo tempo a crianças e a adultos; para se referir a essa característica, a pesquisa dinamarquesa lança mão do termo "articulação dupla" (MYLIUS. 2010, p. 229; cf. EGGENSPERGER, 2017, p. 258).

Na sua discussão do conto, Paul Binding salienta o momento na floresta quando o pinheiro é cortado e levado embora. Nesta situação, o narrador anderseniano deixa bem claro que o sofrimento da árvore não consiste somente na dor física:

The ax struck deep into the marrow, the tree fell with a sigh down on to the ground, it felt a pain, a faintness, it could not think at all about any happiness it had expected, it was sad at having been separated from its home, from that spot from which it had shot forth; it knew well that it would never see the dear old friends, the little bushes and flowers round about, not even the birds (Tradução de BINDING 2014, p. 206). 
O trecho realmente extraordinário expressa empatia com a vida de uma planta de grande porte que está condenada a partir daquele ato de cortar e comercializá-la na cidade. De maneira antropomórfica, a árvore reflete e sente que é arrancada do seu ecossistema onde estava interligada a todas as coisas e seres ao seu redor. $\mathrm{O}$ antropomorfismo do narrador anderseniano fornece aqui o meio para compreender - de forma intuitiva, não científica - que a planta, muito mais do que um mero objeto, é um ser inserido em uma rede de relações ecossociais, dotado de inteligência e sensibilidade. Nas ciências humanas e biológicas, essa perspectiva sobre seres vivos não humanos e principalmente sobre plantas é bem recente. "Plant life", escreve Emanuelle Coccia na sua filosofia das plantas, "is life as complete exposure, in absolute continuity and total communion with the environment. [...] It is the most intense, radical, and paradigmatic form of being in the world." (COCCIA, 2019, p. 5).

Em Hyldemoer (A mãe Sabugueiro, 1845), Andersen evoca a imagem de uma entidade feminina com um vestido tão verde "como as folhas da árvore do sabugueiro, e guarnecido com grandes flores de sabugueiro brancas" (ANDERSEN, 2011, p. 230), uma dríade, a "Mãe Sabugueiro", como explica um velho narrador. Lembramos que no primeiro capítulo d' O vaso de Ouro de E. T. A. Hoffmann, conto clássico do romantismo alemão, o estudante Anselmo deita debaixo de um sabugueiro nas margens do rio Elbe. Nessa situação acontece seu primeiro contato direto com o reino sobrenatural Atlântida, que aparece sob a forma de três serpentes auriverdes enroscadas nos ramos da árvore que se comunicam com o protagonista. No seu conto, Andersen explica a aparência da ninfa arbórea como efeito de elementos naturais: o menino protagonista está resfriado e toma chá quente de sabugueiro feito por sua mãe, enquanto um velho contador de histórias lhe faz companhia. Assim, a fantasia é estimulada naturalmente:

O menininho olhou para a chaleira, a tampa levantava-se mais e mais e as flores de sabugueiro apareciam frescas e brancas, lançavam grandes ramos, do bico se estendiam para todos os lados e se tornavam cada vez maiores, era o mais belo arbusto de sabugueiro, toda uma árvore, penetrava na cama e puxava as cortinas para o lado. Oh! Como floria e cheirava! E no meio da árvore estava sentada uma velha acolhida com um vestido maravilhoso [...] (ANDERSEN, 2011, p. 230). 
Desta forma começa uma narrativa dentro da narrativa que desenvolve a ideia do ciclo da vida, sempre em sintonia com as quatro estações tão marcantes no norte europeu. "O fato básico da trama é a crença popular, presente em várias regiões da Alemanha, de que o sabugueiro é a árvore da Vida, do Destino", comenta-se na edição brasileira (ANDERSEN, 2011, p. 236).

No conto, a figura do velho narrador conecta a ninfa arbórea à antiguidade clássica, e explica que os gregos e romanos chamavam a entidade de Dríade. Sabe-se que para os pastores da Arcádia grega, todas as árvores eram sagradas. Quem danificava uma árvore, machucava sua ninfa habitante e tinha que contar com sua vingança (DEMANDT, 2014, p. 103). No livro VIII das suas Metamorfoses, Ovídio narra a história de Erisícton, que corta um imponente carvalho consagrado à deusa Ceres. Quando o transgressor começa a machucar a árvore, esta reage de forma parecida com o pinheiro no mencionado conto de Andersen quase dois mil anos mais tarde: estremece, solta gemidos, começa a sangrar e depois fala com a voz da sua ninfa, que anuncia a punição do criminoso. Em seguida, Erisícton é castigado com uma fome insaciável, o que o leva a finalmente dilacerar seus membros e devorar assim a si mesmo (OVÍDIO, 2007, p. 217-221).

Dryaden, o conto acima mencionado, é uma obra de Andersen pouco conhecida e menos divulgada mundialmente, também ainda sem tradução publicada em português. De maior extensão, foi o único dos contos andersenianos publicado como caderno avulso (informação de Heinrich Detering in ANDERSEN, 2012, p.489). Na época fazia grande sucesso no mercado livreiro dinamarquês e esgotou rapidamente (MYLIUS. 2010, p. 229). Trata-se de um conto de fadas para adultos - de fadas no sentido de gênero literário, mas também literal, pois a protagonista é uma fada. O título completo da primeira publicação é: Dryaden, et eventyr fra udstillingstiden i Paris I 867 - A dríade, um conto de fadas do tempo da exposição em Paris 1867 (conforme a ficha bibliográfica dinamarquesa em https://andersen.sdu.dk/ forskning/bib/bibsoeg.html? fritekst=dryaden\&ord=0; acesso em 10.10.2019). Deste modo, o conto está claramente ambientado em espaço e tempo contemporâneos aos leitores do final da década 1860. Andersen liga aqui o gênero romântico do Kunstmärchen - conto de fadas de autoria específica - com a temática da modernidade, uma vez que a exposição mundial mencionada no título era vista como manifestação mais imponente e mais avançada do progresso tecnocientífico no continente europeu. 
Dryaden narra, de certa maneira, uma variação da temática central do conto sobre o pinheiro, publicado por Andersen mais de duas décadas antes: a ninfa da jovem castanheira do campo perto de Paris não está satisfeita com sua vida limitada ao lugar e almeja uma vida na grande cidade. A narrativa implica no forte contraste entre a vida rural e a vida urbana. Por causa da exposição mundial, o sonho da dríade se realiza, já que sua árvore é desenterrada e transportada para uma praça no centro da capital, substituindo uma outra que havia morrido no ambiente urbano pouco favorável ao desenvolvimento de plantas de grande porte.

Depois de alguns dias em Paris, a dríade quer conhecer a cidade além da pequena praça, onde sua árvore foi plantada, e visitar também a famosa exposição mundial. Com isso, o destino dessa ninfa arbórea está selado, pois não consegue sobreviver de forma transformada, fora do seu lar natural. Seu desejo de ganhar mobilidade ao sair da árvore somente pode se realizar a partir das condições que uma entidade sobrenatural tinha anunciadas antes:

$$
\begin{aligned}
& \text { You shall go to the city of enchantments! There you shall take root and enjoy the air and the } \\
& \text { sunshine, but your life shall be shortened. The long procession of years that awaited you bere } \\
& \text { in the open country will shrink to a small number. Poor Dryad, it will be your ruin! Your } \\
& \text { longing will grow and your great desire and craving will increase until the tree itself will } \\
& \text { be a prison to you. You will leave your shelter and change your nature; you will fly forth to } \\
& \text { mingle with buman beings, and then your years will shrink to balf of a May fly's lifetime - } \\
& \text { to one night only! The flame of your life will be blown out. The leaves of the tree will wither } \\
& \text { and blow away, never to return (ANDERSEN, 1949). }
\end{aligned}
$$

A moça sai da sua árvore em um vestido tão verde como as folhas novas da jovem árvore e suave como seda. Com essa roupa e uma flor de castanheira no cabelo castanho, ela aprece como a própria deusa da primavera, comenta o narrador. Nas próximas horas, enquanto passa por cenários urbanos diferentes, perde esse aspecto de uma divindade natural e com isso perde completamente sua identidade, o que se manifesta no fato de que sua aparência muda conforme as caraterísticas do lugar que visita. "As the glorious lotus flower, torn from its roots, is carried away by the whirling river, so was the Dryad carried along, and whenever she stopped she changed into a new form; consequently, no one could follow her, recognize her, or even view her" (ANDERSEN, 1949), explica o narrador. "Torn from its roots": o movimento da roça para a 
cidade, da comunidade rural para a capital nacional, que se transforma, durante a exposição, também em capital mundial, leva ao desenraizamento no sentido literal e principalmente figurativo. Não existe mais lugar que para ela poderia ser abrigo; a ninfa é forçada a participar da aceleração da vida urbana moderna: "Away, away! Take flight, without rest!' The May fly that lives but a day has no rest; her flight is her life!", comenta o narrador.

Paris está cheia das maravilhas da técnica moderna: trens e navios a vapor, bondes e ônibus puxados por cavalos, candelabros de gás iluminando a noite, chafarizes magníficos refrescando durante o verão. O cúmulo da modernidade, porém, é a própria Exposição Mundial.

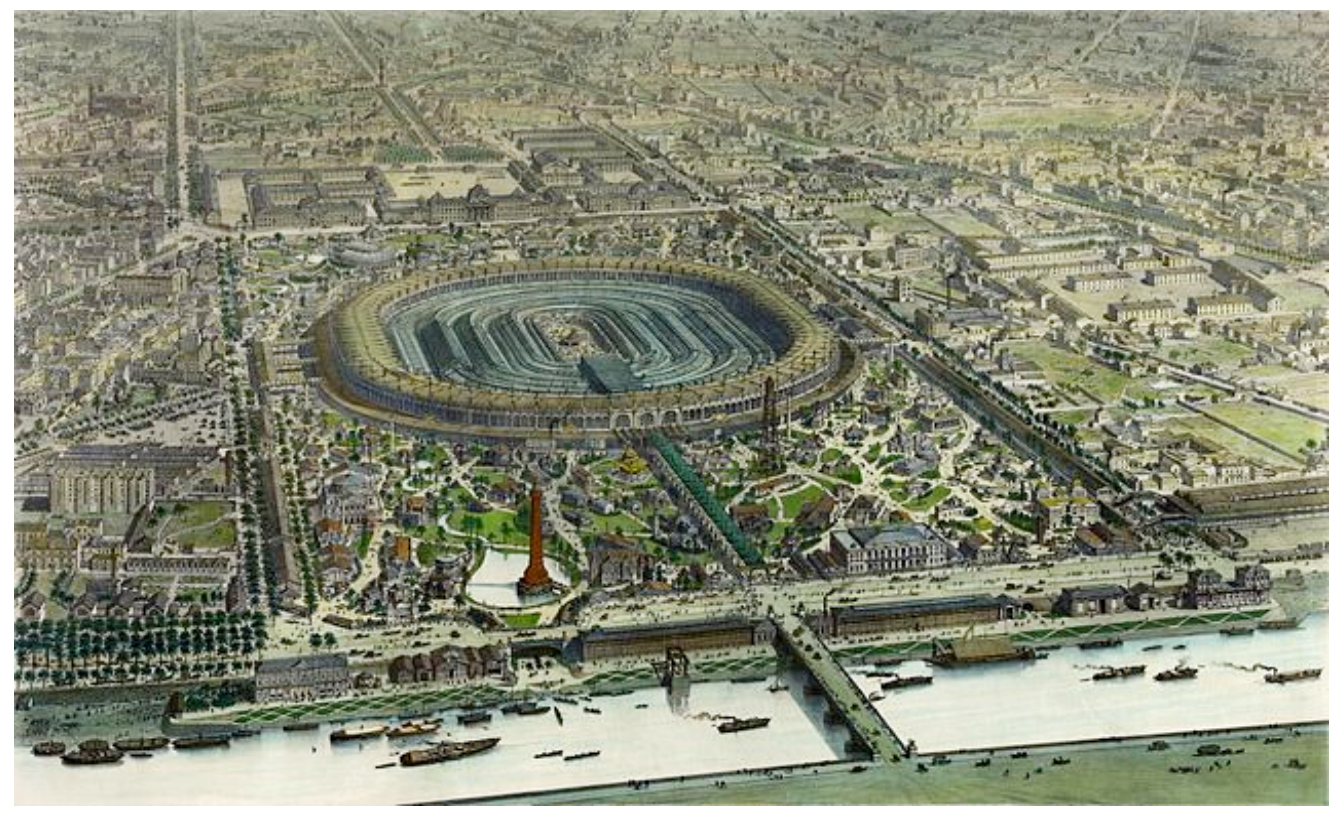

Figura I - Litografia contemporânea da área da exposição mundial em Paris, 1867.

O vocabulário que o narrador usa para descrever essa exibição não deixa de esconder um certo desprezo pelo lugar, que ele chama várias vezes de "palácio moderno de Aladim": "There on the Champ de Mars stood, as on a huge Christmas table, Alladin's castle of art and industry, and around it were knickknacks of greatness from every country; every nation found a memory of its bome." (ANDERSEN, 1949). Knickknacks, no original dinamarquês Nips, alemão Nippes, em português significa nada mais, nada menos do que bugiganga, aqui exposta num castelo de fantasia. Na parte da exposição que mostra o desenvolvimento técnico-industrial reina o bloodless giant: "The giant with bloodless veins moved his steel and iron limbs there in the great circular 
ball." (ANDERSEN, 1949) O Mestre Exangue, Mester blodtøs no original, é uma figura que aparece em vários textos andersenianos sobre técnica e indústria (Deterding in ANDERSEN, 2012, p. 485), uma alegoria que tem semelhança com a famosa metáfora dark satanic mills do romântico inglês William Blake, crítico da ilimitada exploração industrial dos trabalhadores ingleses e da natureza, que ele observou no país onde o capitalismo industrial moderno se desenvolveu mais rápido.

O tempo novo é do progresso com suas maravilhas da técnica moderna, que não deixam mais espaço para o maravilhoso antigo, por exemplo para espíritos naturais. Até o cristianismo como instância espiritual oficial perdeu sua força, visto que a pequena igreja que a dríade procura como abrigo no final não consegue oferecer proteção à moça. A natureza agora fica à mercê dos humanos que deslocam árvores conforme a sua vontade, constroem cachoeiras artificias no centro urbano da capital francesa ou gigantescos aquários que expõem a fauna e a flora das profundidades marítimas, a duzentos quilômetros da costa mais próxima.

Tempo e espaço perdem sua significação antiga; na Paris da exposição mundial de 1867 anunciam-se a globalização econômica e a disneyzação cultural dos séculos XX e XXI. A aceleração a partir dos novos meios de transporte de massa espelha-se, de maneira mimética, no fulminante início do conto:

\footnotetext{
We're going to Paris to see the exposition!

Now we're there! It was a speedy journey, done completely without witchcraft - we went by steam, in a ship and on a railroad. Our time is indeed a time of fairy tales (ANDERSEN, 1949).
}

Nas primeiras três linhas, a temática central já está introduzida. Não existe mais espaço para a magia dos tempos tradicionais; a magia moderna é feita por engenheiros humanos, produto do conhecimento das leis da física e da exploração da natureza, como a partir do uso de carvão mineral e outros combustíveis fósseis que fornecem a energia necessária para as máquinas. Bem-vindos ao antropoceno!

Engana-se quem acha que a primeira pessoa plural no início do conto indicaria um plural majestático. Aqui não se expressa um narrador soberano que fala da altura da sua autoridade, mas um narrador romântico tardio, um contador de histórias anderseniano que sabe 
fingir magistralmente a oralidade, criando assim a comunidade narrativa com seus leitores. "Nós vamos para Paris" - essas primeiras palavras geram desde o início a impressão de imediatez, de uma comunicação aparentemente direta, sem intermediário. Deste modo começa também A rainha da neve, de 1844: "Preste atenção, que vamos começar! Quando chegarmos ao fim da história, saberemos bem mais do que sabemos agora [...]" (ANDERSEN, 2011, p. 199). O narrador anderseniano muitas vezes procura incluir o leitor, pactuar com ele. Diferentemente d'A rainha da neve, constrói-se em Dryaden também uma espécie de moldura narrativa, visto que o mesmo gesto de inclusão se repete no final: "All this has happened and been experienced. We ourselves have seen it, at the Paris Exposition in 1867 , in our time, the great and wonderful time of fairy tales" (ANDERSEN, 1949). Garante-se assim uma veracidade e repete-se no final mais uma vez a temática central da narrativa: o tempo dos contos de fadas tradicionais está acabando, uma vez que as maravilhas saíram do reino da fantasia para serem concretizadas na realidade.

A imagem da morte que o narrador desenvolve no final do conto é bem anderseniana, um exemplo que demonstra a escrita pictural do autor dinamarquês (EGGENSPERGER, 2017, p. 265-267). Quando o sol do novo dia se levanta, "the first ray fell upon the Dryad; her figure was radiant with changing colors, like a soap bubble before it bursts, vanishes, and becomes a drop, a tear, which falls and disappears. Poor Dryad, a dewdrop, only a tear, wept, and swept away!" (ANDERSEN, 1949). Os sonhos da ninfa se desfazem como uma bola de sabão. Ela se torna uma gota de água que logo se transforma em uma lágrima e desaparece. Ao mesmo tempo morre sua árvore que ficou na praça.

Em Dryaden não existe espaço para o pluralismo de diversos modos de existência que caracteriza a obra de Andersen em geral. O desencantamento do mundo - no sentido de Max Weber - está sempre ligado a um reencantamento ideológico, que coloca a tecnociência moderna como o fator mais relevante do desenvolvimento da sociedade. Paris tem se tornado "the city of enchantment" (ANDERSEN, 1949) porque simboliza, no final do Segundo Império, mais do que qualquer outra capital europeia, o mito mais potente do século XIX, o do progresso material ilimitado. O conto de Andersen indica que esse programa mitológico da modernidade europeia tem uma tendência totalitária, pois não reconhece outros modos de existência além dos seus, não admite nenhuma coexistência pacífica. Assim, o espírito arbóreo dos tempos da 
antiguidade greco-romana não pode sobreviver na cidade da civilização e do progresso. Um pensador contemporâneo de Andersen coloca a questão com as seguintes palavras:

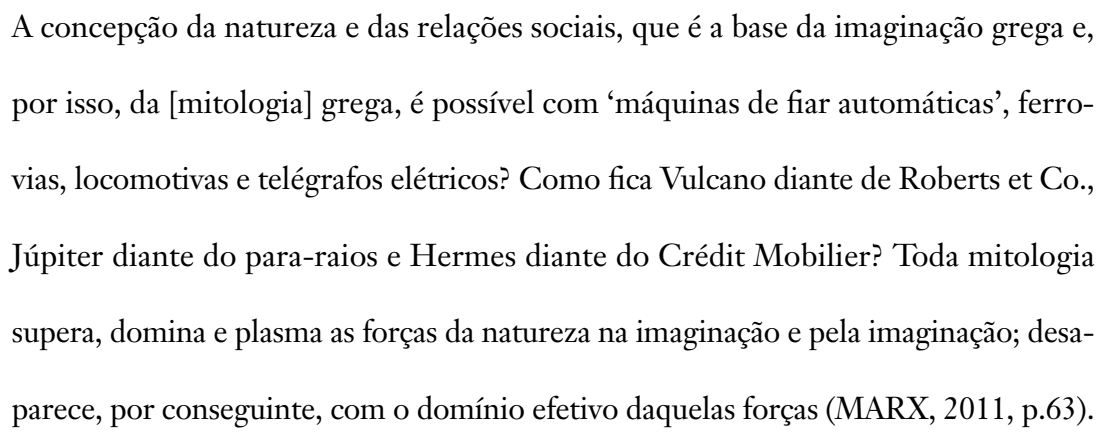

Neste sentido, podemos considerar Dryaden um conto sobre o fim dos contos de fada, uma metanarrativa em que o romântico tardio Andersen reflete com seus meios de contador de histórias sobre a situação do gênero literário romântico por excelência nos tempos da modernidade europeia. O programa romântico de revitalizar antigas visões animistas do mundo termina com Dryaden e outras narrativas da época. Nos dias atuais, as ciências humanas ambientais, não contamos com a presença de entidades espirituais femininas em castanheiras ou carvalhos, mas partimos da diversidade epistemológica e cultural do mundo. O cientista social Boaventura de Sousa Santos fala em ecologia de saberes, "isto é, o reconhecimento da copresença de diferentes saberes e a necessidade de estudar as afinidades, as divergências, as complementaridades e as contradições que existem entre eles" (SANTOS, 2019, p. 28). Ler Andersen possibilita sempre um encontro com um outro tipo de sociedade distinta da nossa contemporânea, conhecer uma perspectiva diferente sobre o papel de humanos e não humanos, uma outra maneira de representar seres vivos e artefatos no momento em que as sociedades capitalistas modernas enfrentam a maior crise ecológica em nível global. 


\section{Referências}

ANDERSEN, Hans Christian. Contos de Hans Christian Andersen. Trad. Silva Duarte. São Paulo: Paulinas, 2011.

ANDERSEN, Hans Christian. The Dryad. In: The Complete Andersen. Ed. e trad. Jean Hersholt. New York: The Limited Editions Club, 1949. Disponível em: https://andersen.sdu.dk/ vaerk/hersholt/TheDryad_e.html. Acesso em 10 out. 2019.

ANDERSEN, Hans Christian. Märchen und Geschichten. Trad. Heinrich Deterding. Stuttgart: Philipp Reclam jun., 2012.

ANDERSEN, Hans Christian. Complete Works. Hastings: Delphi Classics, 2016. [E-book]

BINDING, Paul. Hans Christian Andersen: European Witness. New Haven; London: Yale UP, 2014.

COCCIA, Emanuele. The life of plants: a metaphysics of mixture. Cambridge; Medford: Polity Press, 2019.

DEMANDT, Alexander. Der Baum: eine Kulturgeschichte. Köln; Weimar; Wien: Böhlau, 2014.

EGGENSPERGER, Klaus. O fantástico e o desejo na Menininha dos Fósforos, de H. C. Andersen. Em: Fantástico e seus arredores: figurações do insólito. Org.: Maria Zilda da CUNHA, Lígia MENNA. São Paulo: FFLCH, 2017.

HOFFMANN, E. T. A. O vaso de ouro: uma lenda dos tempos modernos. Trad. Maria Osswald. Lisboa: Vega, s.d.

LATOUR, Bruno. Investigação sobre os modos de existência: uma antropologia dos modernos. Pe- 
trópolis: Vozes, 2019.

MARX, Karl. Grundrisse: manuscritos econômicos de I857-I858. São Paulo: Boitempo; Rio de Janeiro: Ed. UFRJ, 2011.

MYLIUS, Johan de. Der Preis der Verwandlung: Hans Christian Andersen und seine Märchen. Trad. do dinamarquês. Würzburg: Königshausen \& Neumann, 2010.

OVÍDIO. Metamorfoses. Trad. Paulo Farmhouse Alberto. Lisboa: Livros Cotovia, 2007.

RIGBY, Kate. Romanticism and ecocriticism. In: The Oxford Handbook of Ecocriticism. Ed. Greg GARRARD. New York: Oxford University Press, 2014, pp. 60-79.

SANTOS, Boaventura de Sousa. O fim do império cognitivo: a afirmação das epistemologias do Sul. Belo Horizonte: Autêntica, 2019.

WARNER, Marina. Fairy Tale: a very short introduction. New York; Oxford: Oxford UP, 2018. 